\title{
New Enzymatic Gel as Adjuvant Treatment for Wound Healing Processes in Oral Surgery, A Mini-Review and A Case Report
}

\author{
Martina Salvatorina Murgia ${ }^{1}$, Martino Meuli², Carla Mannu ${ }^{3}$, Cinzia Casu ${ }^{1 *}$
}

\author{
${ }^{1}$ DDS, Departement of Surgical Science, Oral Biotechnology Laboratory, University of Cagliari, Italy \\ ${ }^{2}$ DDS, Departement of Surgical, Pediatric and Diagnostic Science, University of Pavia, Italy \\ ${ }^{3}$ Freelance biologist, Cagliari, Italy
}

DOI: $10.36347 /$ sjmcr.2021.v09i01.015

| Received: 06.01.2021 | Accepted: 18.01.2021 | Published: 22.01.2021

*Corresponding author: Cinzia Casu

\section{Abstract}

Introduction: Biological wound healing consists of a cascade of cellular and molecular events. Healing processes can be influenced by a variety of factors, both local and systemic. Cutaneous and oral wounds can be either accidental or surgical. Biochemical components contained in animal or plant origin substances may promote the repair of the integrity of injured tissues by supporting blood clot formation, stimulating neo-angiogenesis, protecting the wound from infection, and inducing connective tissue formation. Topical gel applications based on mucus secreted by various snail species, alone or combined with other therapeutic options, may accelerate tissue repair and promote tissue normalization after surgical incisions, traumatic wounds, periodontal and peri-implant injuries, and infections. Materials and Methods: A literature search of the electronic databases PubMed and Google Scholar was conducted to identify which scientific articles reported the clinical use of snail slime gels as bio-stimulants in adjuvant tissue repair processes. Specifically, our focus was to identify whether clinical cases and scientific papers proposed Gelenzyme ${ }^{\circledR}$ as an adjuvant in oral wound or injury healing processes as we did in our clinical practice. Results and Discussion: Three papers and/or academic posters presenting clinical cases were identified. Besides, we decided to report our own clinical case of a patient who presented with a mechanical complication of a single implant-supported prosthetic crown. Crown fracture, detachment from the abutment and exposure of the emergent abutment in the oral cavity resulted in the adjacent lingual border erosion. The traumatic lingual injury was treated with Gelenzyme ${ }^{\circledR}$ Clinical healing appeared more rapid and rather successful with reduced local symptomatology and the absence of adverse reactions. The number and diffusion of reported clinical cases using Gelenzyme ${ }^{\circledR}$ are still limited. Conclusion: Pharmacological properties such as anti-inflammatory, antioxidant, antimicrobial, and analgesic may play a critical role in the wound healing process and may also be directly provided by natural origin substances from both animals and plants. In special chemical formulations for clinical purposes, mucus produced by snails has some advantages in this regard. It is up to researchers to perform further molecular analyses to assess the exact composition of mucosal constituents produced by snails. The biological potential of snail slime components used alone or combined with other therapy modalities such as laser and ozone may influence the course of wound healing in oral surgery. Clinical results are currently promising. Snail slime is already being used in cosmetics and dermatology.

Keywords: topical treatment for oral trauma, enzymatic gel, gel for oral trauma.

Copyright $\odot 2021$ The Author(s): This is an open-access article distributed under the terms of the Creative Commons Attribution 4.0 International License (CC BY-NC 4.0) which permits unrestricted use, distribution, and reproduction in any medium for non-commercial use provided the original author and source are credited.

\section{INTRODUCTION}

Inflammation is a common defensive response of animal cells to harmful stimuli, including chemical and physical irritants and pathogens [1]. The inflammation mechanism is a chain of dynamic, defensive, and restorative biological phases that include cellular and vascular events with specific humoral secretions. These pathways involve physical location changes of white blood cells, plasma, and fluids towards the inflammatory site $[2,3]$.
Inflammation can be divided into acute and chronic. The acute inflammation phase guides the initial wound healing stages to restore lost tissue integrity and normal tissue function. The initial inflammatory phase is followed by a proliferative phase and a remodeling phase. The wound healing process is complex and dynamic and refers to a cascade of cellular and molecular interactions [4]. In medicine, the expression "restitutio ad integrum" is frequently used concerning the outcome of the biological process characterized by 
Martina Salvatorina Murgia et al., Sch J Med Case Rep, Jan, 2021; 9(1): 55-60

the complete healing of the diseased organ or tissue with the definitive disappearance of all associated morbid phenomena without any functional sequelae [5].

Surgical wound healing in the oral cavity occurs in a high-bacterial environment. In the absence of local risk factors, a surgical wound of limited extent may heal by first intention after the surgeon has repositioned the flaps with the margins juxtaposed against each other and without tension. Shorter times are required for the normalization of tissue integrity. If the wound margins cannot be juxtaposed and some degree of separation remains among them, healing proceeds by second intention. The space between the wound margins is filled by granulation tissue, subsequently evolving into fibrous tissue and cicatricial tissue [6].

Although inflammation is a beneficial phenomenon, inflammatory process progression often results in undesirable outcomes such as pain, edema, redness, loss of function of inflamed tissues, and oxidative stress. In fact, in the immediate postoperative period, one of the most important concerns for both the surgeon and the patient is how to control pain, edema, and infection. The presence of foreign materials and local infection, within the wound microenvironment, for example, are two risk factors that reduce tissue repair capacity [6].

Many systemic diseases also lower healing potential. Non-steroidal anti-inflammatory drugs (NSAIDs) have been developed to relieve inflammatory symptoms, particularly pain. However, treatment with NSAIDs causes adverse side effects, including gastrointestinal, renal, and cardiovascular toxicity [7$10]$.

Recently, several natural products with antiinflammatory properties have been introduced for clinical purposes. Several scientific studies have focused on the anti-inflammatory properties of numerous natural products, mainly of plant origin and less frequently of animal origin.

Mucous secretions derived from snails are radically innovating skin therapy and cosmetics. In particular, among the various possible clinical applications of snail mucus, wound healing management offers a rather promising opportunity. Snail mucus is already an active ingredient in numerous products, both cosmetic and para pharmaceutical. Its chemical composition needs to be further investigated. The snail body is entirely covered by a mucous substance (named snail secretion or snail mucus or snail slime). It is secreted mainly for moisturizing and protective purposes to reduce friction during locomotion. This mucus is secreted by epidermal glands, called pedal glands, located at the snail's foot.
The mucus is very similar to a hydrogel and is still used in cosmetics, medicine, and bioengineering [11, 12].

Such mucus contains an unidentified list of biochemical and ionic compounds. As reported in some studies in Helix aspersa muller, the chemical compounds in such mucus reveal the absence of cytotoxicity on human fibroblasts. On the contrary, human fibroblasts would be stimulated to reorganize their cytoskeleton and their cell motility. Cell migration, if enhanced by snail mucus, may support the wound repair process. Besides, snail mucus protects cells from apoptosis and stimulates fibroblast proliferation [12].

Snail slime has become a significant component in cosmetic products due to its content of many biochemical substances with useful skin healing properties, including allantoin, elastin, collagen, and hyaluronic acid [4]. Other components include proteins, sulfur/non-sulfur glycosaminoglycans, minerals, glycemic acid, polyphenols, and sugars [12].

In addition, snail slime has also been reported to be antibacterial [13, 14], antioxidant, regenerative [15-18] and anti-tumoral [19]. In fact, the plant enzymatic cascade initiates the cellular reproduction kinetics of millions of cells per second. The anti-tumor potential of snail slime has not yet been sufficiently investigated. Some authors report that snail slime exhibits anti-tumor activity against human melanoma cells [20].

Interestingly, snail slime extracted from Achatina fulica resulted in faster skin healing than the healing without its application [21]. Snail mucus from Helix aspersa has already demonstrated its clinical use to manage skin wounds and treat chronic bronchitis [12].

A study on the effects of natural compounds on wounds in traditional Iranian medicine mentions animals such as earthworms (Clitellata), snails (Gastropoda), and shellfish (Bivalvia) as sources from which substances with biological effects adjuvant to tissue healing can be obtained. The interconnection of human medicine and biological studies on animals and plants to identify their potential benefit for a wide range of oral and cutaneous wounds is certainly of great interest $[11,12,22,23]$.

The detailed list of snail slime components, which may promote wound healing, is not entirely known. Other snails such as Eobania vermiculata, Theba pisana and Monacha obstructa have been investigated. The mucous secretions of each of these species may differ in chemical composition [23]. 
Among the constituents of snail slime are numerous chemical compounds such as glycosaminoglycans and calcium. They can stimulate blood coagulation, fibroblast proliferation, and angiogenesis phenomena. The closure of the virtual space on both sides of the wound may therefore be faster. In the absence of contaminating foreign bodies and local infection, normalization of the wound proceeds just as rapidly. If snail slime has antimicrobial properties, it may be helpful in this regard.

Some studies have already evaluated in experimental terms the possibility of using snail glycosaminoglycans to promote wound healing in the diabetic foot. A study emphasizes the pro-angiogenic activity of snail glycosaminoglycans, along with the reduction of edema and inflammation already in the early stages of the biological repair process [24].

Recent work in the literature shows a proven statistically significant $(\mathrm{p}<0.05)$ healing ability of periodontal pockets in Wistar rats treated by debridement and the local application of oral snail slime compared to other study groups [25], which was also confirmed by another study [26].

This work aims to perform a scientific review and analysis of the therapeutic effects of a compound based mainly on snail slime and oleos substances, Gelenzyme ${ }^{\circledR}$ (3P ImplaFavourite, Turin, Italy) in the medical field and with a focus in the dental field. Gelenzyme ${ }^{\circledR}$ boosts cellular kinetics after its application on the wound, resulting in cell proliferation together with an excellent analgesic effect. Gelenzyme ${ }^{\circledR}$ can be used for the treatment of periodontal pockets and peri-implantitis. It can also be used in post extractive sites and surgery before flap closure.

We report a clinical case involving the application of Gelenzyme ${ }^{\circledR}$ on a traumatic lingual lesion in a 63-year-old male patient due to a mechanical complication derived from a single implant-retained prosthetic crown.

\section{Materials and Methods}

Bibliographic research in PubMed and Google Scholar electronic databases was performed to detect scientific papers reporting the use of snail-mucousbased products and Gelenzyme ${ }^{\circledR}$ in the general medical field. The papers concerning animals, those not fully accessible, and those in languages different from English and Italian were excluded. We also took advantage of reading and reviewing some posters from the University of Turin, presenting clinical cases using gel enzyme in oral surgery.

The keywords used were: Gelenzyme, snail slime, properties, wound healing, oral pathology, dermo-cosmetics in various combinations.

\section{RESULTS}

Three clinical cases were finally included in this review. The clinical cases surveyed in the literature made use of Gelenzyme ${ }^{\circledR}$ in a variety of therapeutic medical applications. Specifically, one application was reported in dermatologic medicine and two applications in oral medicine. Of the two cases found, one application involved periodontal therapy. The other application was in implant surgical therapy. All papers showed the beneficial effects of topical application of Gelenzyme ${ }^{\circledR}$ in the healing processes of surgical wounds, periodontal and peri-implant lesions, and the absence of side effects. Clinical and pharmacological data on Gelenzyme ${ }^{\circledR}$ were found to be still limited. This review reveals that clinical publications on Gelenzyme ${ }^{\circledR}$ are still in their embryonic stage. In fact, the five clinical cases presented derive from poster presentations related both to Gelenzyme ${ }^{\circledR}$ manufacturer and to research conducted at the University of Turin.

\section{Clinical application of gelenzyme ${ }^{\circledR}$ in oral surgery: a case report}

A 63-year-old male patient came to our private dental clinic. The medical history revealed previous gastro-esophageal reflux disease and symptoms (GERD/S) and mild hypertension. A history of mild prostatic hypertrophy was also reported. The patient was on oral lansoprazole medical therapy.

The patient had undergone implant-prosthetic therapy on location 3.6. As is well known, implantretained prostheses can exhibit mechanical complications during their functional use in the oral cavity of patients. In this clinical case, the mechanical complication involved a single crown retained on an endo-osseous implant. Patients with these complications may experience varying degrees of dissatisfaction. A crown cemented on an abutment can lose its retention due to a variety of factors. The most common mechanical complication is usually attributable to occlusal overload, depending on the implant position in the dental arch, the occlusal relationship of the prosthetic crown to the antagonist dentition, the prosthetic emergence angulation, and the persistence of parafunctional habits. The patient, in fact, was suffering from rather intense episodes of clenching. These episodes had determined the fracture of the prosthetic body and its detachment from the implant-abutment. The movement of the tongue, against the abutment without its crown, caused local trauma and an injury to the mucosal integrity of the left lingual border in the anterior two-thirds of the tongue body. Masticatory force during eating and friction against the abutment resulted in a painful and localized erosion. The erosive lesion in question did not clinically exhibit an extensive keratosis because the patient, immediately after the loss and mechanical failure of the prosthetic crown, came to our practice, thus avoiding severe iatrogenic chronic friction. Based on the above, it was immediately 
Martina Salvatorina Murgia et al., Sch J Med Case Rep, Jan, 2021; 9(1): 55-60

excluded that the observed lingual erosion could be attributable to GERD/S acid reflux. The lingual dorsum and lingual undersurface venter were intact.

While waiting to rehabilitate the edentulous site with a new prosthetic crown and manage parafunctional habits, we decided to deliver a topical application of Gelenzyme ${ }^{\circledR}$ to promote the mucosal and submucosal healing process of the affected lingual site. A few hours after application, the patient was asymptomatic. Almost complete healing is observed after only 2 days of clinical follow-up. The gel application proved to be quite versatile and achieved full patient satisfaction.

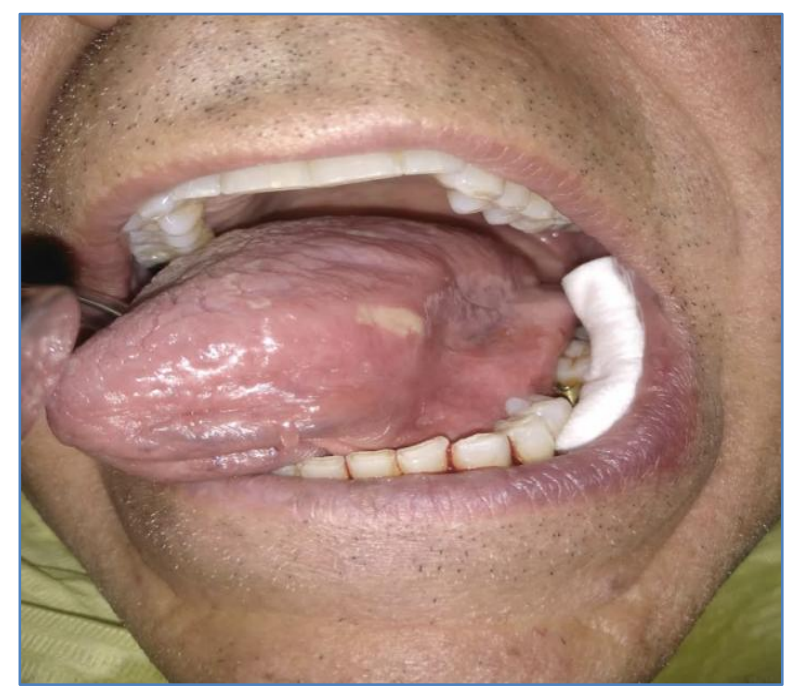

Fig-1

A traumatic lesion with distinct borders and slightly keratotic on the left lingual border adjacent to the edentulous site where the abutment is missing its crown. The patient reported localized traumatic episodes during mastication and after losing the prosthetic crown due to mechanical failure.

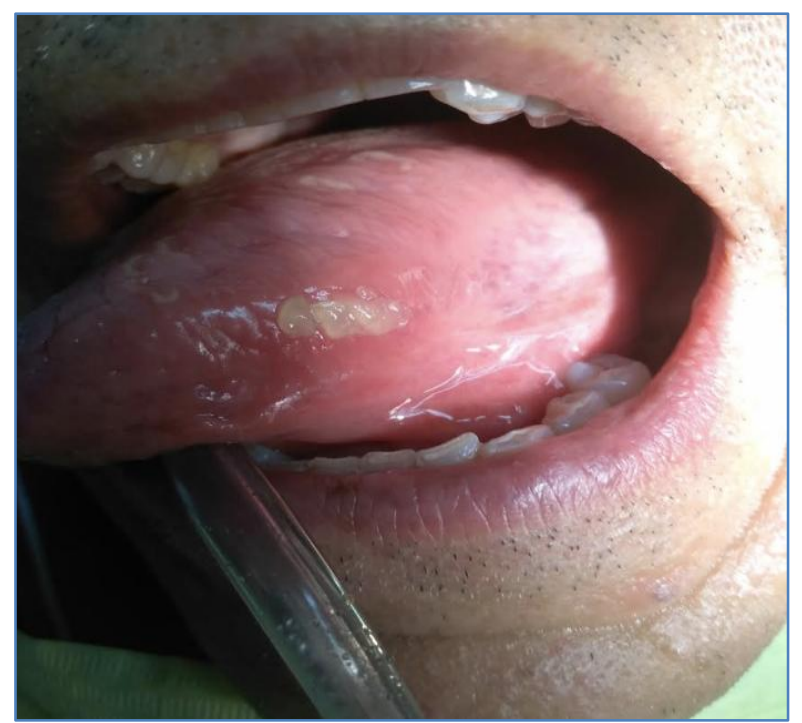

Fig-2
Topical application of Gelenzyme ${ }^{\circledR}$ to the site of injury. The gel is dense and well confined. Adjuvant healing support for normalization of mucosal integrity of the left border of the tongue is expected.

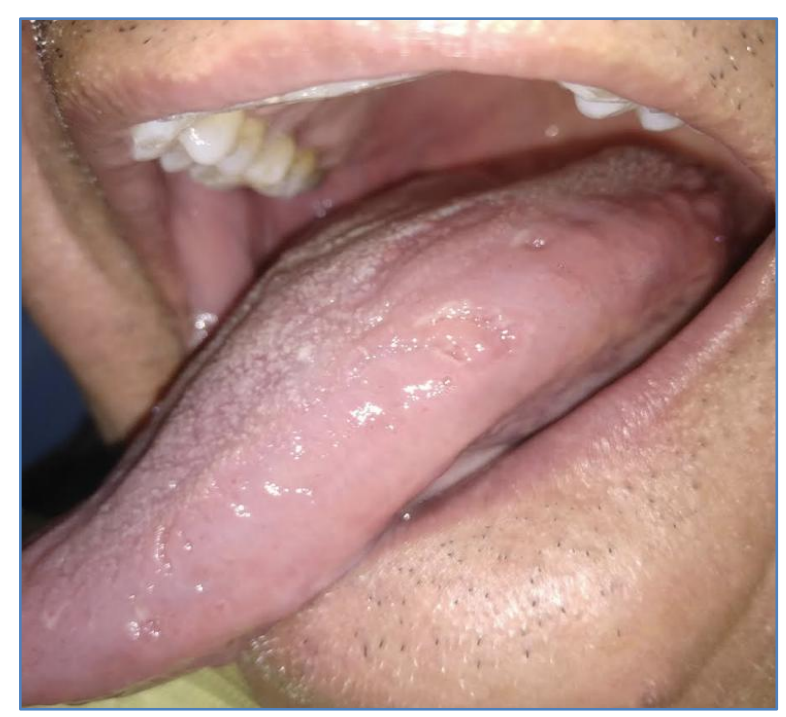

Fig-3

Clinical follow-up at 2 days. The patient reported neither discomfort nor local symptoms. Clinical aspects of healing are clearly visible both in terms of color and morphological appearance.

\section{DisCUSSION}

The first clinical case included in this review reported the use of Gelenzyme ${ }^{\circledR}$ for dermo-cosmetic purposes in two clinical cases to facilitate the healing process of two skin wounds. The first clinical case reported the application of Gelenzyme ${ }^{\circledR}$ on a surgical incision performed due to the enucleation of a sebaceous cyst in the posterior cervical region. After only two applications, at 3 and 8 weeks respectively, complete healing and absence of scarring on the skin were observed. The second clinical case reported a wound of the palmar skin of the hand of a diabetic patient. The lesion exhibited significant healing after only one week after application [27].

Sedran et al. conducted a preliminary study (the fourth clinical case included in this review) to evaluate the efficacy of the therapeutic synergy between administering a $810 \mathrm{~nm}$ diode laser therapy and Gelenzyme $®$ in surgical wound healing and periodontal maintenance peri-implant physiological stability. Specifically, they divided patients into 3 groups according to the treatment assigned to them: treatment with diode laser alone (G1), treatment with Gelenzyme ${ }^{\circledR}$ alone (G2), and combined-synergic treatment (G3). The results showed that the group treated with both the diode laser and Gelenzyme® presented immediate hemostasis and rapid healing with subsequent re-epithelialization of the surgical wound [28]. 
Martina Salvatorina Murgia et al., Sch J Med Case Rep, Jan, 2021; 9(1): 55-60

The last study reviewed, conducted by the same clinical team from the previous work, used the diode laser, Gelenzyme $\AA$, and Liquidozone ${ }^{\circledR}$ to evaluate periodontal and peri-implant tissue healing times (Fig. 4). The advantage of the liquid formulation of ozone is the significantly reduced dispersion of the chemical principle compared to the gaseous form. The results showed significant site healing after implant placement [29].

Mucosal extracts derived from snails have long been used in the treatment of wounds. The exact identification of the molecular components contained in snail slime is still in progress. Snail slime and the components it contains offer promise as a therapeutic component to stimulate healing and normalization of skin wounds, oral mucosal or periodontal wounds and lesions, and even chronic injuries of various origins, such as the diabetic foot.

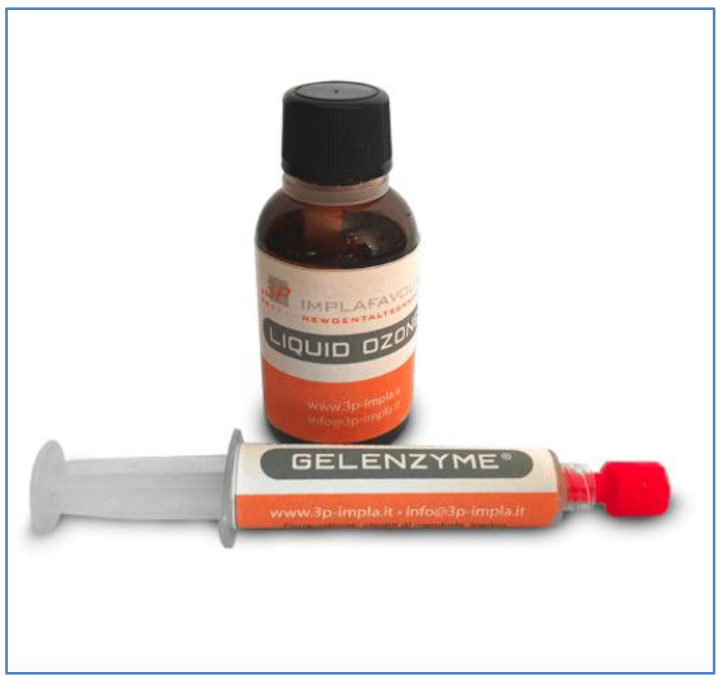

Fig-4

Gelenzyme ${ }^{\circledR}$ and Liquidozone ${ }^{\circledR}$

\section{CONCLUSION}

Current clinical works indicate that Gelenzyme ${ }^{\circledR}$ represents a valuable adjuvant treatment for healing processes, especially in the oral medical field. Combining Gelenzyme $\AA$ with other therapies further improves the healing responses of certain types of oral and cutaneous wounds or injuries.

However, further clinical studies, especially comparative studies, are needed to obtain more effective results. To accurately evaluate the mechanism of action of a snail mucus product for wound management, it is essential to proceed with a series of experimental analyses. Both chemical and microbiological characterization of the mucous secretions produced by the snail must be performed. The absence of cytotoxicity to human cells and tissues in which snail mucus is applied topically must also be documented. Snail slime, already widely used in cosmetics and dermatology, is biocompatible and offers significant biological advantages.

Molecular interactions between the chemical components of snail mucus and cell populations that actively promote wound healing need to be further investigated. Direct topical application of snail slime to the surgical wound in oral surgery or the histologic bed of a wound should ideally be easy to administer, safe, effective, easy to access, and low cost.

Adjuvant wound healing gels may soon become part of the adjuvant products and therapies that oral surgeons must have available in their practices to address a wide range of both surgical and traumatic wound scenarios. It is probably possible that snail-based oral gels could also be commercialized over the counter upon careful prescription or clinical indication for use.

Gel-like mucus from snails has biomimetic potential in many industries such as pharmaceutical, cosmetic, medical, and food [11].

\section{ACKNOWLEDGMENTS}

We thank the biomedical inventor Massimo Randisi for his scientific contributions on the application of Gelenzyme $\AA$ and Liquidozone ${ }^{\circledR}$ that he designed.

\section{REFERENCE}

1. Isailovic N, Daigo $\mathrm{K}$, Mantovani A, Selmi C. Interleukin-17 and innate immunity in infections and chronic inflammation. Journal of autoimmunity. 2015 Jun 1;60:1-1.

2. Jones C. "Understanding Pathophysiology. 5th Edition Sue E Huether and Kathryn L McCance. 2012; 1159 pages Elsevier: ISBN 978-0-32307891-7 Cost: £67.99,’ J. Ren. Nurs., 2012

3. Anwikar S, Bhitre M. Study of the synergistic antiinflammatory activity of Solanum xanthocarpum Schrad and Wendl and Cassia fistula Linn. International journal of Ayurveda research. 2010 Jul;1(3):167.

4. Gubitosa J, Rizzi V, Fini P, Laurenzana A, Fibbi G, Veiga-Villauriz C, Fanelli F, Fracassi F, Onzo A, Bianco G, Gaeta C. Biomolecules from snail mucus (Helix aspersa) conjugated gold nanoparticles, exhibiting potential wound healing and antiinflammatory activity. Soft Matter. 2020.

5. "restitutio in integrum", Treccani Encyclopedia, Italy, https://www.treccani.it/vocabolario/restitutioin-integrum/

6. Chiapasco M, Manual of Oral Surgery, Edra, Third Edition

7. Silverstein FE, Faich G, Goldstein JL, Simon LS, Pincus T, Whelton A, Makuch R, Eisen G, Agrawal NM, Stenson WF, Burr AM. Gastrointestinal toxicity with celecoxib vs nonsteroidal anti-inflammatory drugs for 
osteoarthritis and rheumatoid arthritis: the CLASS study: a randomized controlled trial. Jama. 2000 Sep 13;284(10):1247-55.

8. Harirforoosh S, Asghar W, Jamali F. Adverse effects of nonsteroidal antiinflammatory drugs: an update of gastrointestinal, cardiovascular and renal complications. Journal of Pharmacy \& Pharmaceutical Sciences. 2013;16(5):821-47.

9. Bacchi S, Palumbo P, Sponta A, Coppolino MF. Clinical pharmacology of non-steroidal antiinflammatory drugs: a review. Anti-Inflammatory \& Anti-Allergy Agents in Medicinal Chemistry (Formerly Current Medicinal Chemistry-AntiInflammatory and Anti-Allergy Agents). 2012 Jun 1;11(1):52-64.

10. Chan FK, Graham DY. Prevention of nonsteroidal anti- inflammatory drug gastrointestinal complications-review and recommendations based on risk assessment. Alimentary pharmacology \& therapeutics. 2004 May;19(10):1051-61.

11. Greistorfer S, Klepal W, Cyran N, Gugumuck A, Rudoll L, Suppan J, von Byern J. Snail mucusglandular origin and composition in Helix pomatia. Zoology. 2017 Jun 1;122:126-38.

12. Trapella C, Rizzo R, Gallo S, Alogna A, Bortolotti D, Casciano F, Zauli G, Secchiero P, Voltan R. HelixComplex snail mucus exhibits pro-survival, proliferative and pro-migration effects on mammalian fibroblasts. Scientific reports. 2018 Dec 5;8(1):1-0.

13. Etim LB, Aleruchi C, Obande GA. Antibacterial properties of snail mucus on bacteria isolated from patients with wound infection. Microbiology Research Journal International. 2016:1-9.

14. Iguchi SM, Aikawa T, Matsumoto JJ. Antibacterial activity of snail mucus mucin. Comparative Biochemistry and Physiology Part A: Physiology. 1982 Jan 1;72(3):571-4.

15. Pitt S. "Snail slime: the science behind molluscs as medicine,"Conversat., 2019.

16. Agustina L, Shoviantari F, Aditya D. Stability Test of Glycosaminoglycan and Achasin in Snail (Achatina fullica) Slime and Its Gel Formulation. International Journal of Drug Delivery Technology. 2020 Mar 25;10(1):05-8.

17. Brieva A, Philips N, Tejedor R, Guerrero A, Pivel JP, Alonso-Lebrero JL, Gonzalez S. Molecular basis for the regenerative properties of a secretion of the mollusk Cryptomphalus aspersa. Skin Pharmacology and Physiology. 2008;21(1):15-22.

18. Iglesias- de la Cruz MC, Sanz- Rodríguez F, Zamarrón A, Reyes E, Carrasco E, González S, Juarranz A. A secretion of the mollusc Cryptomphalus aspersa promotes proliferation, migration and survival of keratinocytes and dermal fibroblasts in vitro. International journal of cosmetic science. 2012 Apr;34(2):183-9.

19. Teerasak E, Thongararm P, Roytrakul S, Meesuk L, Chumnanpuen P. Prediction of anticancer peptides against MCF-7 breast cancer cells from the peptidomes of Achatina fulica mucus fractions. Computational and structural biotechnology journal. 2016 Jan 1;14:49-57.

20. Ellijimi C, Hammouda MB, Othman H, Moslah W, Jebali J, Mabrouk HB, Morjen M, Haoues M, Luis J, Marrakchi N, Essafi-Benkhadir K. Helix aspersa maxima mucus exhibits antimelanogenic and antitumoral effects against melanoma cells. Biomedicine \& Pharmacotherapy. 2018 May 1;101:871-80.

21. Harti AS, Sulisetyawati SD, Murharyati A, Oktariani M, Wijayanti IB. The effectiveness of snail slime and chitosan in wound healing. International Journal of Pharma Medicine and Biological Sciences. 2016 Jan 1;5(1):76.

22. Fana SE, Ahmadpour F, Rasouli HR, Tehrani SS, Maniati M. The effects of natural compounds on wound healing in Iranian traditional medicine: A comprehensive review. Complementary Therapies in Clinical Practice. 2020 Dec 1:101275.

23. Sallam AA, El-Massry SA, Nasr IN. Chemical analysis of mucus from certain land snails under Egyptian conditions. Archives of Phytopathology and Plant Protection. 2009 Sep 1;42(9):874-81.

24. Wu Y, Zhou Z, Luo L, Tao M, Chang X, Yang L, Huang $\mathrm{X}, \mathrm{Hu} \mathrm{L}, \mathrm{Wu}$ M. A non-anticoagulant heparin-like snail glycosaminoglycan promotes healing of diabetic wound. Carbohydrate Polymers. 2020 Nov 1;247:116682.

25. IGAAP S, IB PM, THAHIR H, AA RS, NYM MA, IWP S, TGB M. The Effectiveness Of Giving Snail Slime (Acatina Fulica) On The Healing Of Pocket On The Wistar Rats With Periodontitis. International Journal of Applied Pharmaceutics. 2019 Aug 15:19-21.

26. Swastini IG, Mahadewa TG, Widyadharma IP. Alveolar bone osteoclast profile in the periodontitis Wistar rats model with the snail slime (Achatina fulica) application. Open access Macedonian journal of medical sciences. 2019 May 31;7(10):1680.

27. Tapparo A, De Martino M. GELENZYME. Dermocosmetico naturale agli enzimi vegetali per la cinetica cellulare. Personal comunication. https://3p-impla.it/prodotti/gel-enzyme-e-ozonoliquido/

28. Sedran A, Randisi M, Carossa S. LLLT ed enzimi nella terapia parodontale e chirugica implantare. Poster at the VIII Congresso Nazionale S.I.L.O. (Società Italiana Laser in Odontostomatologia) 1213 June 2015, Roma.

29. Sedran A, Sedran A, Randisi M, Carossa S. Terapia con laser a diodi $810 \mathrm{~nm}$, enzimi ed ozono liquid: metodi terapeutici complementari nella terapia parodontale e implantare. Poster at the XXIII Collegio dei Docenti Universitari di Discipline Odontostomatologiche. 14-16 April 2016, Roma. 